\title{
Microstructure Characteristics and Properties of HVOF Sprayed Ni-Based Alloy Nano-h-BN Self-Lubricating Composite Coatings
}

\author{
Xiaofeng Zhang, Long Zhang, and Zhenyi Huang \\ School of Metallurgical Engineering, Anhui University of Technology, Maanshan 243032, China \\ Correspondence should be addressed to Xiaofeng Zhang; egzxf@ahut.edu.cn
}

Received 2 July 2015; Accepted 26 October 2015

Academic Editor: Dae-Eun Kim

Copyright ( 2015 Xiaofeng Zhang et al. This is an open access article distributed under the Creative Commons Attribution License, which permits unrestricted use, distribution, and reproduction in any medium, provided the original work is properly cited.

\begin{abstract}
A Ni-based alloy/nano-h-BN self-lubricating composite coating was produced on medium carbon steel by high velocity oxygen fuel (HVOF) spraying technique. The powder feedstocks for HVOF spraying were prepared by ball milling and agglomerated the nano-h-BN with Ni-based alloy powders. The microstructure and mechanical properties of coatings have been investigated. With the increasing of h-BN contents, some delaminations appeared gradually in the coatings and a continuous network with h-BN phase embedded formed in the metallic matrix. The average microhardness of the self-lubricating coating was a little lower for the addition of soft solid lubricant. The friction coefficient of coatings is in the ranges of $0.38-0.48$ and $0.38-0.52$ at ambient temperature and $400^{\circ} \mathrm{C}$, respectively. The maximum bonding strength of coatings reached $23.83 \mathrm{MPa}$.
\end{abstract}

\section{Introduction}

Solid lubricating coatings are typically employed in extreme environment applications in which liquid lubricants and greases are invalid [1]. For example, in the forming process of top grade aluminum alloy automobile panels at temperature of 400 to $500^{\circ} \mathrm{C}$, the liquid lubricants and greases are easy to stick onto the mould surface, which results in the deterioration of mould working condition. Postcleaning and disposal of these lubricants and greases is difficult and costly and has a significant influence on the production efficiency $[2,3]$. Conventional solid lubricants, such as graphite and molybdenum disulfide $\left(\mathrm{MoS}_{2}\right)$, are unfriendly to environment because of black color and unacceptable above $400^{\circ} \mathrm{C}$ for their inadequate oxidation resistance in moderately humid air $(0.30 \%$ $\mathrm{RH}$ ) [4]. The challenge is to find a material that has better chemical stability in the air above $400^{\circ} \mathrm{C}$ and still provides low friction and wear protection.

Hexagonal Boron Nitride (h-BN) has recently been known as a new type of ceramic material. It has fine lubricating performance with lower friction coefficient, high thermal conductivity, and excellent high temperature resistance, together with moderate cost, white color, and nonpoisonous
$[5,6]$. For these characteristics, $\mathrm{h}-\mathrm{BN}$ is suitable to serve as solid lubrication phase in composite coating. In addition, the Ni-based self-fluxing alloy has better antioxidant performance under high temperature with good wear resistance and has good wettability to ferrite substrate [7]. Therefore, Ni45 self-fluxing powder is chosen as coating matrix material.

There are several methods to produce solid lubricant coatings [1], such as physical vapor deposition process (PVD), chemical vapor deposition process (CVD), laser cladding, thermal spraying, compound plating, and pasting. Amongst these methods, high velocity oxygen fuel (HVOF) is a competitive method to produce high-quality coating. By burning hydrocarbon gas in oxygen, the spray devices are designed to achieve supersonic expansion of burning gas; the gas exit velocity is above $1000 \mathrm{~m} / \mathrm{s}$, so that the particles are deposited onto substrate to form a dense and strong adhesion coating $[8,9]$.

The aim of this paper is to investigate the microstructure and tribological properties of HVOF-sprayed Ni45-h$\mathrm{BN}$ composite coatings at ambient temperature and $400^{\circ} \mathrm{C}$, respectively. Moreover, bonding strength of coatings was tested according to ASTM C-633-79 standard. 


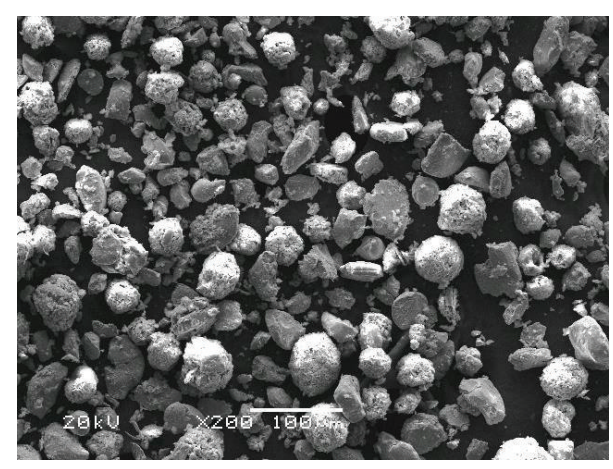

(a)

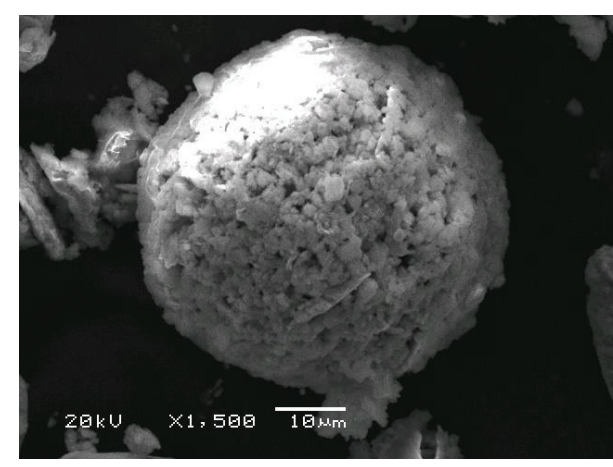

(b)

FIGURE 1: Morphologies of the composite powders. (a) Agglomerated powders; (b) a particle of the agglomerated powders.

TABLE 1: Properties of the original powders for HVOF spraying.

\begin{tabular}{lcc}
\hline Properties & Ni45 & h-BN \\
\hline Density $\left(\mathrm{g} \cdot \mathrm{cm}^{-3}\right)$ & 8.4 & 2.2 \\
& Cr: $12 \sim 15 \%, \mathrm{~B}: 2.0 \sim 3.0 \%$, & \\
Content (wt.\%) & Si: $2.0 \sim 3.5 \%$, & $\geq 99.9 \%$ \\
& C: $0.3 \sim 0.6 \%, \mathrm{Fe} \leq 12 \%$, \\
Li: allowance & \\
$\left(10^{-6} \cdot \mathrm{K}^{-1}\right)$ & $12.37\left(\right.$ at $\left.540^{\circ} \mathrm{C}\right)$ & $8.58($ at \\
Thermal conductivity & $14.7 \sim 15.5\left(\right.$ at $\left.300^{\circ} \mathrm{C}\right)$ & $15.16($ at \\
$\left(\mathrm{W} \cdot \mathrm{m}^{-1} \cdot \mathrm{K}^{-1}\right)$ & $\left.300^{\circ} \mathrm{C}\right)$ \\
Mean particle size & $37.5 \sim 60 \mu \mathrm{m}$ & $80 \mathrm{~nm}$ \\
\hline
\end{tabular}

\section{Experimental Procedure}

2.1. Materials and Processing. Coating materials used in the experiment were nano-h-BN powders and Ni45 self-fluxing powders with the mean composition of $15 \mathrm{Cr}-3 \mathrm{~B}-3.5 \mathrm{Si}-0.6 \mathrm{C}$ $12 \mathrm{Fe}$ - balance $\mathrm{Ni}$ (wt.\%). Particle sizes of raw coating powders were $80 \mathrm{~nm}$ and $37.5 \sim 60 \mu \mathrm{m}$ for $\mathrm{h}-\mathrm{BN}$ and Ni45 self-fluxing powder, respectively, as tabulated in Table 1 . Before spraying, the coating materials were blended in a certain ratio by weight and ball milled to submicron size and then agglomerated with some organic binders into about $45 \mu \mathrm{m}$ particles by spraydried method. Figure 1 shows the agglomerated particles used for thermal spraying. The substrate was a medium carbon steel with a composition of Fe-0.45C-0.3Si-0.6Mn (wt.\%), the surface of which was ground to $\mathrm{Ra} 0.8 \mu \mathrm{m}$ and then rinsed with ethanol followed by acetone and grit blasted by corundum of size 20-24 meshes before HVOF spraying. The agglomerated particles were sprayed with high velocity and high thermal energy onto the substrate to form a dense coating, as illustrated in Figure 2, the total thickness of which was in the range of $350 \sim 400 \mu \mathrm{m}$.

The spraying was carried out with a KY-HVO/AF system. Kerosene and oxygen were used as a fuel and combustionsupporting gas, respectively. During spraying, chamber pressure was $0.9 \mathrm{MPa}$, oxygen pressure was $1.4 \mathrm{MPa}$, oxygen flux was $24 \mathrm{~g} / \mathrm{s}$, kerosene pressure was $1.5 \mathrm{MPa}$, and kerosene flux was $8 \mathrm{~g} / \mathrm{s}$. The spraying distance was kept at $380 \mathrm{~mm}$;

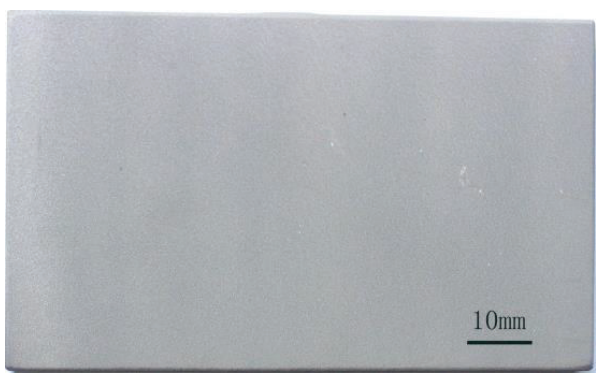

FIGURE 2: Macrograph of HVOF-sprayed Ni45-hBN composite coating.

nitrogen was used as powder carrier gas, which was worked at $0.35 \mathrm{MPa}$.

The prepared self-lubricating coatings were characterized by using a scanning electron microscope (SEM) equipped with an energy dispersive spectrometer (EDS) and an X-ray diffraction (XRD) with $\mathrm{CuK}_{\alpha}$ radiation. For a better observation of coating microstructure, some of the polished coatings were etched with a mixture of concentrated hydrochloric acid and concentrated nitric acid by volume ratio $3: 1$ for 3 minutes. The hardness of the coatings was measured by a Buehler-II microhardness tester with a load of $200 \mathrm{~g}$ and dwell time of $15 \mathrm{~s}$.

2.2. Frictional Properties Test. The friction and wear behavior of coatings was determined by a pin-on-ring tribometer at room temperature and $400^{\circ} \mathrm{C}$, respectively. The schematic of the pin-on-ring pair is illustrated in Figure 3. The ring size is $\varnothing 138 \mathrm{~mm} \times 30 \mathrm{~mm}$, which was a ball bearing steel AISI E52100 with a hardness of HRC 60-62. The size of pin specimens cut from the substrate was $6 \mathrm{~mm}$ long $\times 4 \mathrm{~mm}$ wide $\times 10 \mathrm{~mm}$ high, which was fixed in a holder of the test rig. Prior to the tests, the ring and pin specimens were polished with 600 grits abrasive paper and then cleaned with acetone. The friction and wear tests were conducted at a sliding velocity of 1.0 or $2.0 \mathrm{~m} / \mathrm{s}$ and a load of 20 or $40 \mathrm{~N}$, at ambient temperature and $400^{\circ} \mathrm{C}$. 


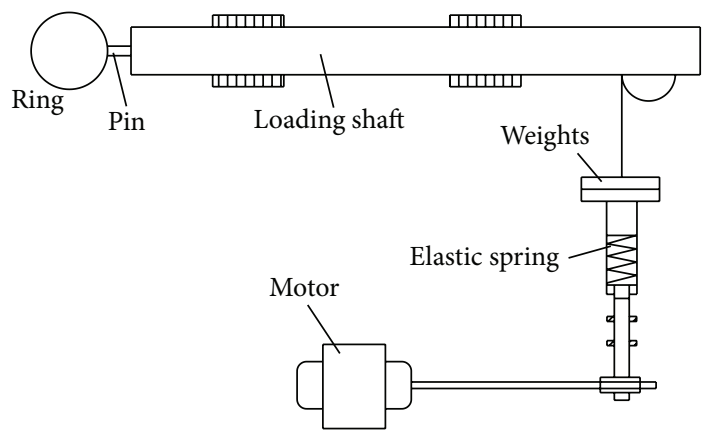

FIgURE 3: The schematic of the pin-on-ring tribometer.

2.3. Adhesive Strength Test. The adhesive strength of the coatings was measured by pull-off test method in accordance with ASTM C-633-79 standard. The universal test machine (Shimadzu AG-1 $250 \mathrm{KN}$, Japan) allows force measurements accuracy of $\pm 1 \%$ of indicated test force. The specimens were prepared individually with a diameter of $15 \mathrm{~mm}$ steel substrate at the same thermal spray processing. The commercially available adhesive used was an epoxy resin (E-7), which was applied on the coated surface and joined the counter block. After joining, the specimens were fixed in a clamping fixture to keep the coaxiality between the coated specimen and the counter block and kept in the oven at $100^{\circ} \mathrm{C}$ for 3 hours, and then the samples were cooled to room temperature. The adhesive tests were carried out in the single-tension mode, with a tension velocity of $1 \mathrm{~mm} / \mathrm{min}$. The adhesion strength of the coatings was evaluated when the test specimen was broken. For each coating, the average value of three test pieces was used as the indicator of adhesive strength.

\section{Results and Discussion}

3.1. Microstructure of Composite Coatings. Microstructures of the coatings with different components are shown in Figure 4. Figure 4(a) shows the cross section of the coating containing $5 \mathrm{wt} . \% \mathrm{~h}-\mathrm{BN}$. Dense coatings without evident delaminations were observed. There was a clear gap between the coating and the substrate, which may affect the adhesive strength of coatings. Some delaminations appeared gradually in the coatings with increasing h-BN contents, as shown in Figure 4(b). The metallic matrix formed a continuous network in which h-BN phase was embedded. The black zones in the microstructure were either the embedded h-BN or porosity (shown in Figures 4(b1) and 4(b2)).

Microhardness of the coating and interface was tested randomly at five different locations, and three indentations were performed for every location. The average value for each location was shown in Figure 5. The results of the microhardness, as expected, indicated a significant difference in the values with respect to the content of $\mathrm{h}-\mathrm{BN}$ in coating. With the increase of h-BN added to Ni45 matrix, the average microhardness of the coatings showed a little decrease trend. Even in a given component coating, there was a slight hardness variation through the coating's cross section. Two reasons may be responsible for these phenomena; one reason is that h-BN is a soft phase in coating in contrast with matrix phase; the presence of solid lubricant phases in a hard coating increased the scatter in hardness values measured on the coating and decreased the hardness of whole coating. Another is the porosity in coating and the distribution of the phase structure of the metal matrix and solid lubricant phases, which leads to little fluctuations and variations of hardness across the coating. This shows that the above reasons play an important role in variation of the hardness measurements for a given coating [10].

Figure 6 shows the XRD patterns of the as-sprayed coatings, which confirmed the presence of h-BN and $\mathrm{Ni}-$ based alloy solid solution in the coating. Owing to B and $\mathrm{N}$ being light elements, XRD analysis only indicated certain amounts of h-BN in the coating after thermal spraying. Part of the agglomerated powder particles may disintegrate during spraying, releasing some small size particles with h$\mathrm{BN}$, which have insufficient mass to be deposited onto the substrate. The substantial amounts of h-BN in coating may much less than the solid lubricant presence in the powder particles agglomerated with raw materials.

3.2. Friction Coefficient of Coatings. Figure 7 shows the friction coefficients of as-sprayed coating, which, namely, contains $10 \mathrm{wt} . \% \mathrm{~h}-\mathrm{BN}$, sliding against AISI E52100 bearing steel at ambient temperature and $400^{\circ} \mathrm{C}$, respectively. As shown in Figure 7, the coatings exhibit the lower average friction coefficient with comparison to the coating without solid lubricants. The friction coefficient of Ni45-hBN composite coatings is in the ranges of $0.38-0.48$ and $0.38-0.52$ at ambient temperature and $400^{\circ} \mathrm{C}$, respectively. Comparing to the friction coefficient of Ni45 coating (about 0.61 ), the composite coating improved the tribological properties. In addition, test temperature has a little effect on the friction coefficient of the coatings. Some fluctuation around the average value has a tendency to increase with increasing temperature. The fluctuation of friction coefficients at $400^{\circ} \mathrm{C}$ was particularly noticeable compared to at room temperature after shorter running-in period, which may be related to coating properties and the transfer films of tribocouple interfaces. Moreover, the effects of load on the friction coefficient of coating are also shown in Figure 7. At ambient temperature, the loads of $20 \mathrm{~N}, 40 \mathrm{~N}$ almost have the same friction coefficient without regard for the effects of unstable factors in the initial stage of testing. Yet the load of $40 \mathrm{~N}$ has lower friction coefficient compared to that of $20 \mathrm{~N}$ at $400^{\circ} \mathrm{C}$.

3.3. Adhesive Strength of Coatings. Adhesive strength is one of the most important factors in thermal spray coating since it directly relates to the durability of the coating. If as-sprayed coatings ended with failure in the adhesives before debonding between the coating and substrate, then the critical adhesive strength could not be determined. The only information obtained by these experimental assessments is that the coating system has excellent adhesive strength. But if fractures occurred in the coatings, the real adhesion strength of coatings is equal to the experimental values. 


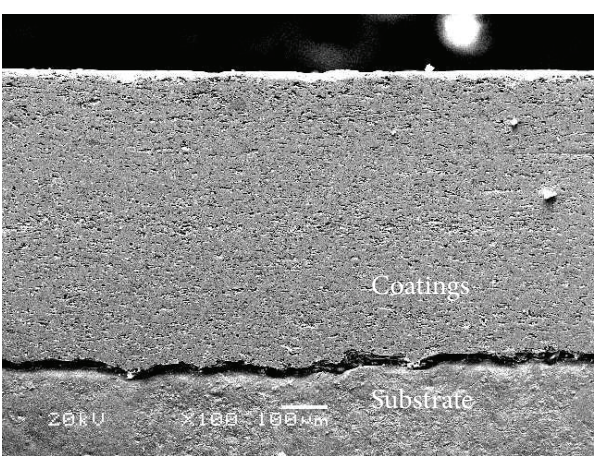

(a)

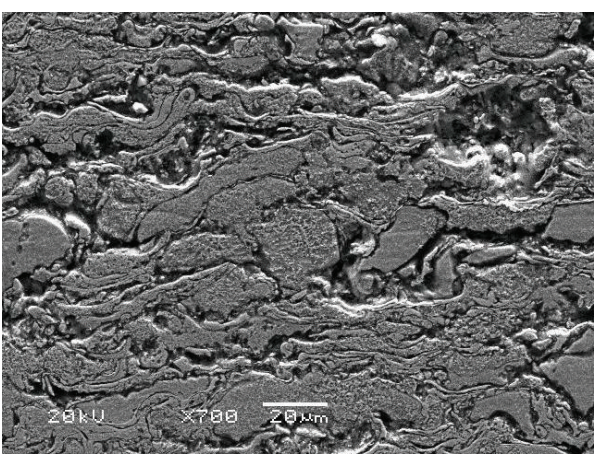

(b1)

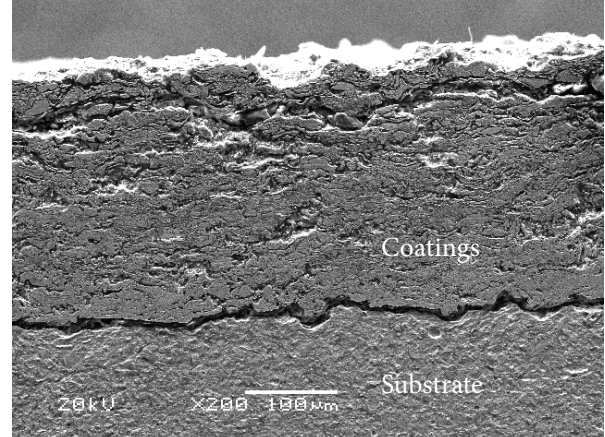

(b)

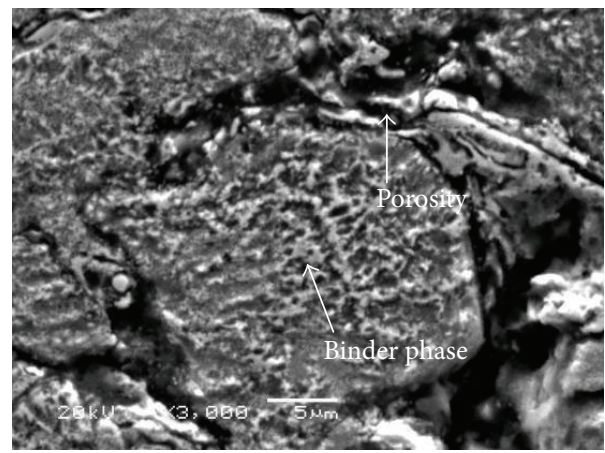

(b2)

FIGURE 4: Microstructure of the coatings produced with different percentages of composite powders. (a) Ni45-hBN, 5 wt.\% h-BN; (b) Ni45hBN, 10 wt.\% h-BN; (b1), (b2) high magnification structure of 10 wt.\% h-BN coating.

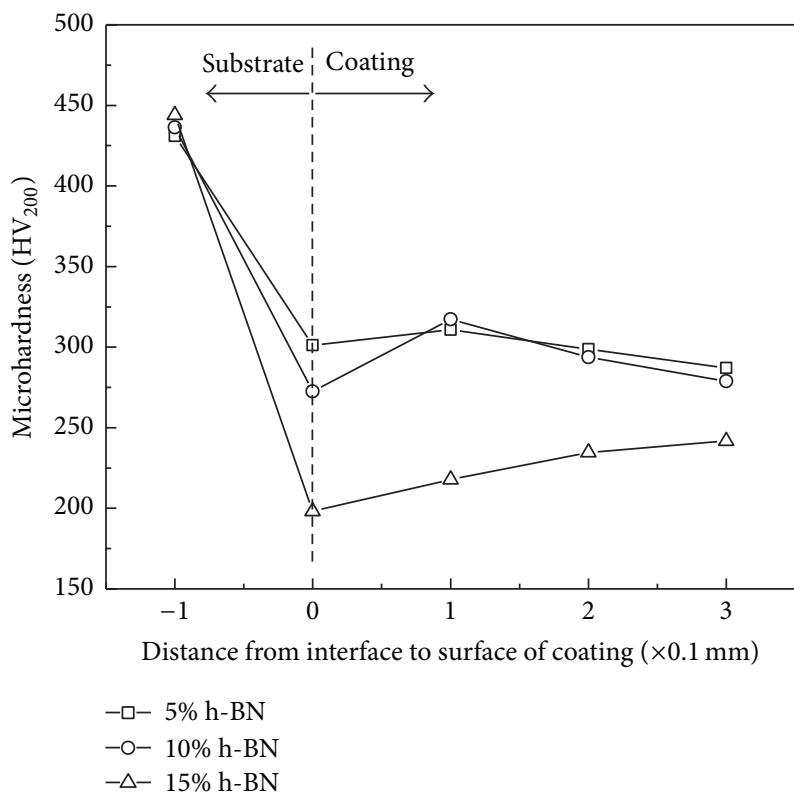

FIGURE 5: Microhardness of cross-sectional coating.

Cracks initiated in coating while pulling off test machine were loaded to a certain extent and propagated through the agglomerated particles, and then fractures occurred in vulnerable regions of the coating. As shown in Figure 8,

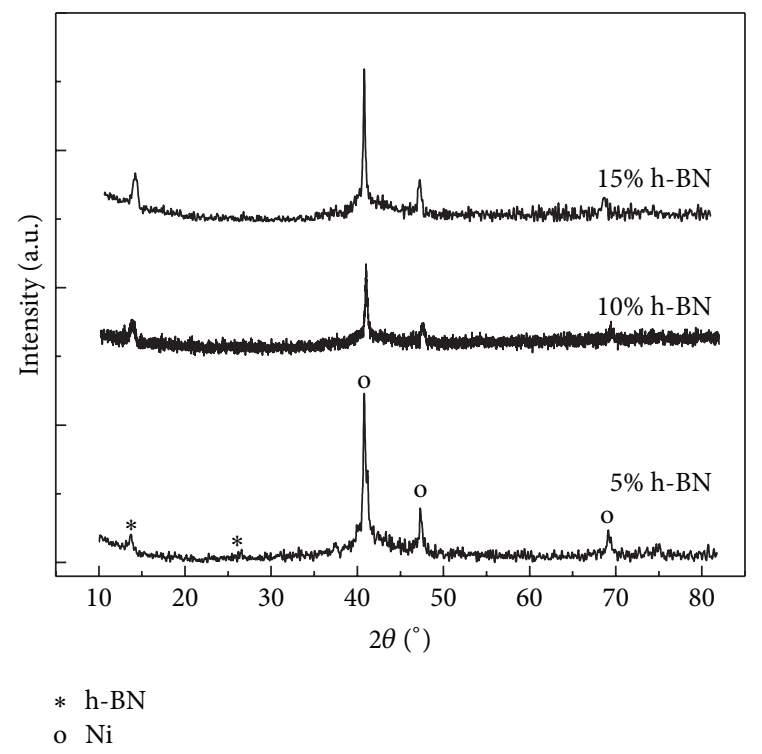

FIGURE 6: XRD patterns of the Ni45-h-BN composite coating.

for Ni45-h-BN composite coatings with the component of $5 \mathrm{wt} . \%, 10 \mathrm{wt} . \%$, and $15 \mathrm{wt} . \% \mathrm{~h}$-BN, the fracture load reached $4.2 \mathrm{kN}, 2.7 \mathrm{kN}$, and $1.5 \mathrm{kN}$, converting into tensile stress that was equivalent to $23.83 \mathrm{MPa}, 15.08 \mathrm{MPa}$, and $8.3 \mathrm{MPa}$. 


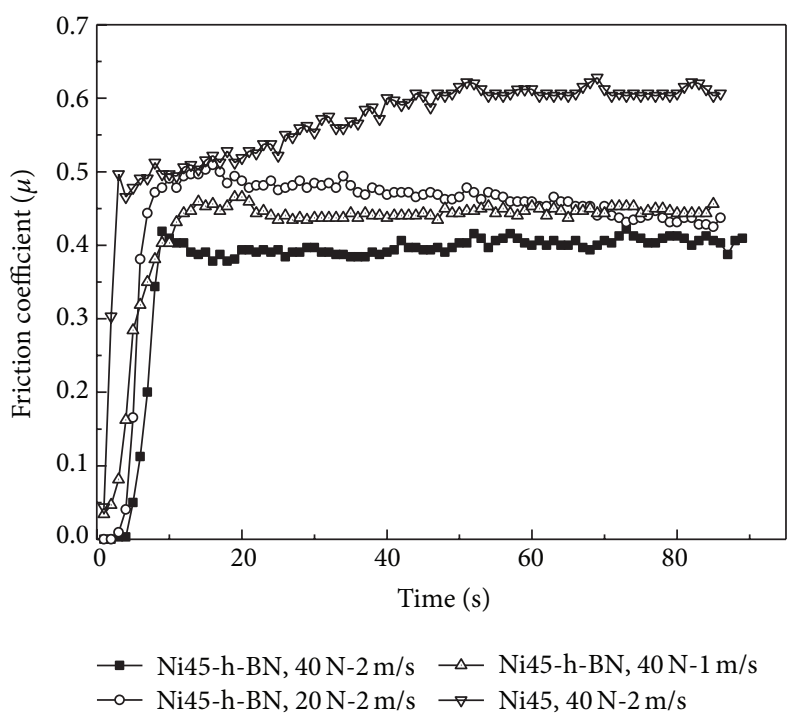

(a) At ambient temperature

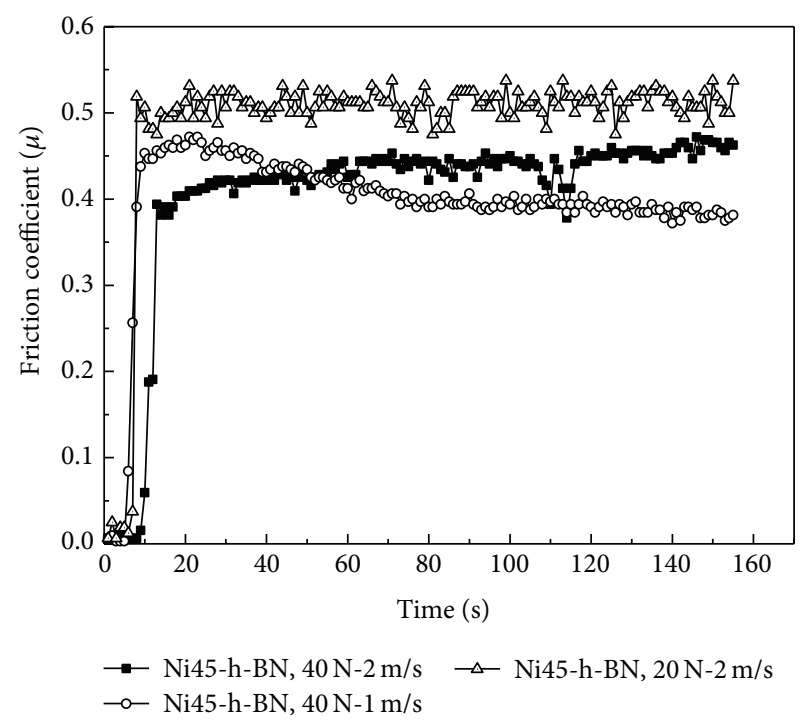

(b) At $400^{\circ} \mathrm{C}$

FIGURE 7: Friction coefficient of coatings at different temperature.

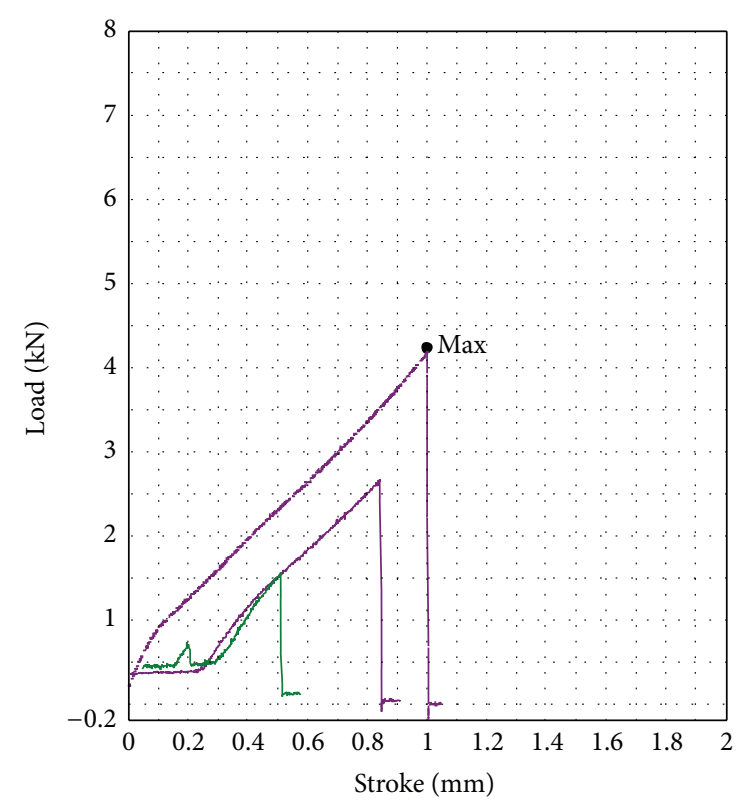

FIGURE 8: The curve of adhesive strength of as-sprayed coating.

Generally, it is considered that the adhesive strength is relative to bonding modes between the coating and the substrate, such as mechanical interlocking, physical bonding, or metallurgical bonding [11, 12]. For Ni-based self-fluxing alloy is a low melting point, partial Ni45 alloy in particles surface has been semimelted in spraying process, which filled the valleys of rough substrate and formed a certain mechanical interlock bond at the interface of coating/substrate. Moreover, the partial melted particles were liable to being oxidized in high pressure oxygen environment, which may significantly affect the bonding strength between coating and substrate and the interconnection of coating, and lead to the increasing of porosity in coating. In addition, for blending nano-h-BN into Ni45 powders, the agglomerated particles are low-density, which severely decreased the impulse of particles to substrate in spraying process, and lead to a weak bonding between the coating and substrate, as well as coating inside. As shown in Figures 9(a) and 9(b), tensile fracture of the composite coating was basically a brittle fracture in nature, where the cleavage fracture is dominant but with a small fraction of dimply patterns at the composite particles.

Figures 9(c) and 9(d) show micrographs of the cracked coatings. Some protuberances and cavities, whose shapes are like the agglomerated particles, were created on the surface of fracture, which would be the imprints of agglomerated particles when breaks are generated along the boundary of particles.

\section{Conclusion}

(1) A feedstock containing nano-h-BN was successfully produced by ball milling and agglomerated to meet the requirement of HVOF spraying process.

(2) A composite coating with certain adhesion strength was achieved by using HVOF technique. With the increasing of h-BN content, delaminations appeared gradually in the coatings and the microhardness of the coating decreased significantly.

(3) The friction coefficients of as-sprayed coating are in the ranges of $0.38-0.48$ and $0.38-0.52$ at ambient temperature and $400^{\circ} \mathrm{C}$, respectively.

(4) Adhesive strength of as-sprayed coating is lower compare to that of other metal alloy powders with HVOF process; the consistence of h-BN with $\mathrm{Ni} 45$ and the low density of h-BN would be responsible for it. 


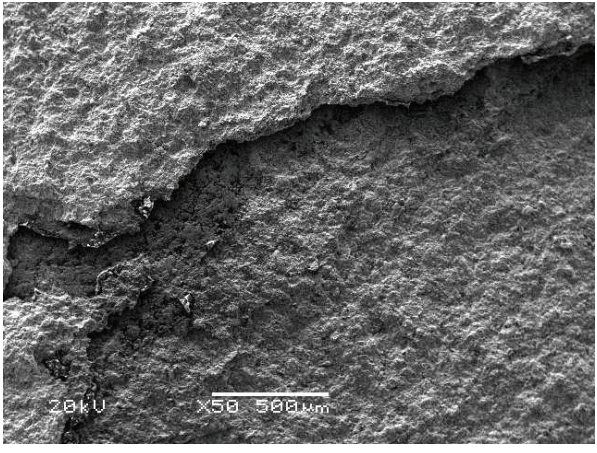

(a)

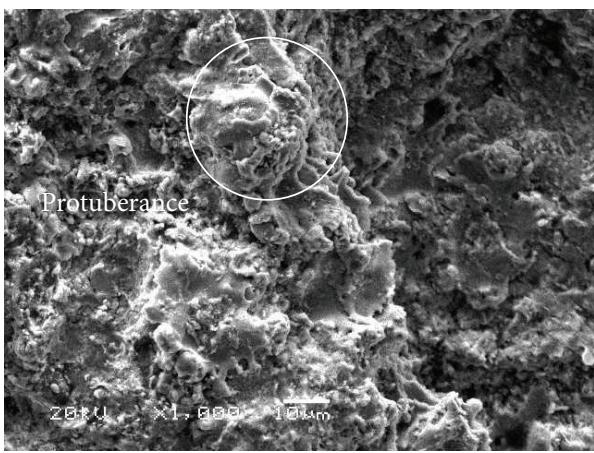

(c)

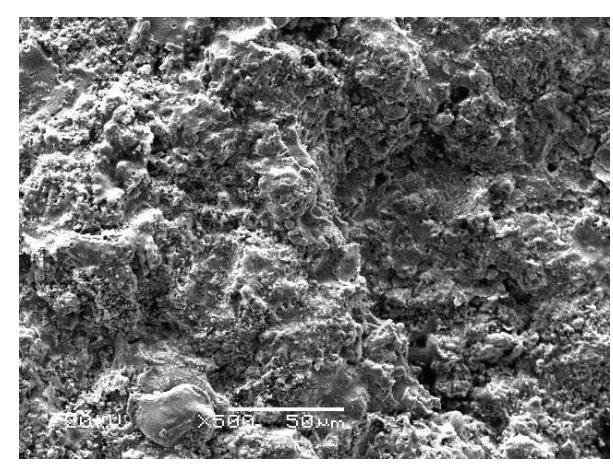

(b)

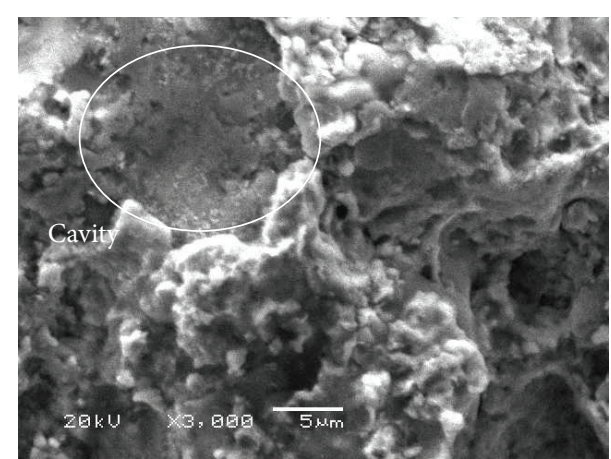

(d)

FIGURE 9: Fractured surface morphologies of as-sprayed coating after the tensile adhesive test. (a) Macrograph of fractured surface; (b) micrograph of fractured surface; (c), (d) high magnification.

\section{Conflict of Interests}

The authors declare that there is no conflict of interests regarding the publication of this paper.

\section{Acknowledgments}

The authors would like to thank Aihua. Wang and Xianglin. Zhang, School of Materials Science \& Engineering, Huazhong University of Science \& Technology, for their technical assistance in the coating preparation. The financial support of this work was provided by National Natural Science Foundation of China (no. 50575081).

\section{References}

[1] C. Donnet and A. Erdemir, "Solid lubricant coatings: recent developments and future trends," Tribology Letters, vol. 17, no. 3, pp. 389-397, 2004.

[2] M. Meiler, M. Pfestorf, M. Geiger, and M. Merklein, “The use of dry film lubricants in aluminum sheet metal forming," Wear, vol. 255, no. 7-12, pp. 1455-1462, 2003.

[3] T. Horiuchi, S. Yoshihara, and Y. Iriyama, "Dry deep drawability of A5052 aluminum alloy sheet with DLC-coating," Wear, vol. 286-287, pp. 79-83, 2012.

[4] P. D. Fleischauer and J. R. Lince, "A comparison of oxidation and oxygen substitution in $\mathrm{MoS}_{2}$ solid film lubricants," Tribology International, vol. 32, no. 11, pp. 627-636, 1999.
[5] S. Mahathanabodee, T. Palathai, S. Raadnui, R. Tongsri, and N. Sombatsompop, "Dry sliding wear behavior of SS 316L composites containing h-BN and $\mathrm{MoS}_{2}$ solid lubricants," Wear, vol. 316, no. 1-2, pp. 37-48, 2014.

[6] J. Eichler and C. Lesniak, "Boron nitride (BN) and BN composites for high-temperature applications," Journal of the European Ceramic Society, vol. 28, no. 5, pp. 1105-1109, 2008.

[7] X. Zhang, A. Wang, X. Zhang, and Z. Huang, "Microstructure and properties of laser clad nano-Ni- encapsulated h-BN/CaF composite coating," Journal of Huazhong University of Science and Technology, vol. 37, no. 1, pp. 9-13, 2009.

[8] C. Sun, L. Guo, G. Lu, Y. Lv, and F. Ye, "Interface bonding between particle and substrate during HVOF spraying," Applied Surface Science, vol. 317, pp. 908-913, 2014.

[9] B. Wielage, A. Wank, H. Pokhmurska et al., "Development and trends in HVOF spraying technology," Surface \& Coatings Technology, vol. 201, no. 5, pp. 2032-2037, 2006.

[10] J. Voyer and B. R. Marple, "Tribological performance of thermally sprayed cermet coatings containing solid lubricants," Surface \& Coatings Technology, vol. 127, no. 2-3, pp. 155-166, 2000.

[11] Y.-Y. Wang, C.-J. Li, and A. Ohmori, "Examination of factors influencing the bond strength of high velocity oxy-fuel sprayed coatings," Surface \& Coatings Technology, vol. 200, no. 9, pp. 2923-2928, 2006.

[12] S. Kamnis, S. Gu, T. J. Lu, and C. Chen, "Numerical modeling the bonding mechanism of HVOF sprayed particles," Computational Materials Science, vol. 46, no. 4, pp. 1038-1043, 2009. 

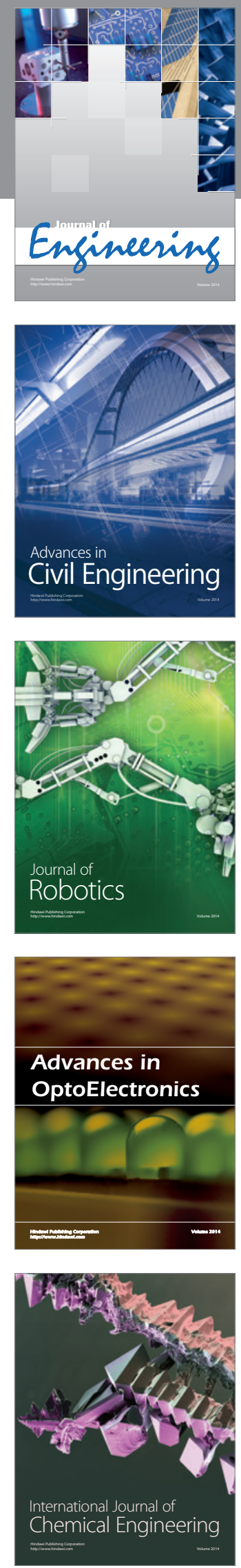

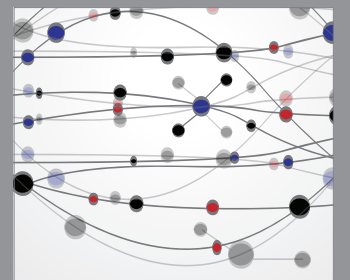

The Scientific World Journal
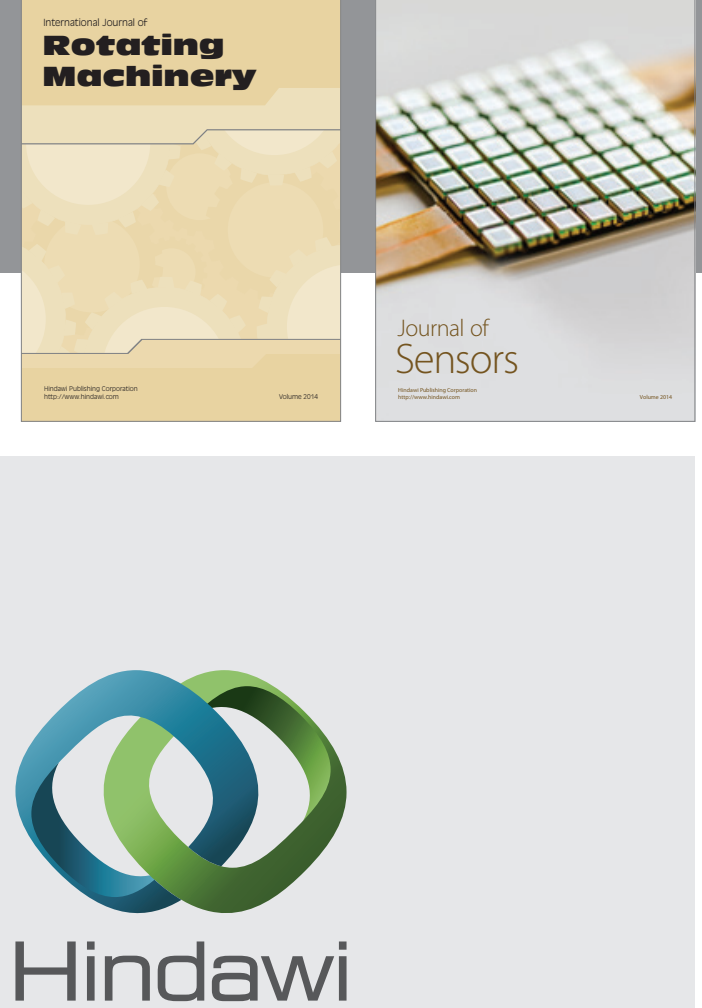

Submit your manuscripts at http://www.hindawi.com
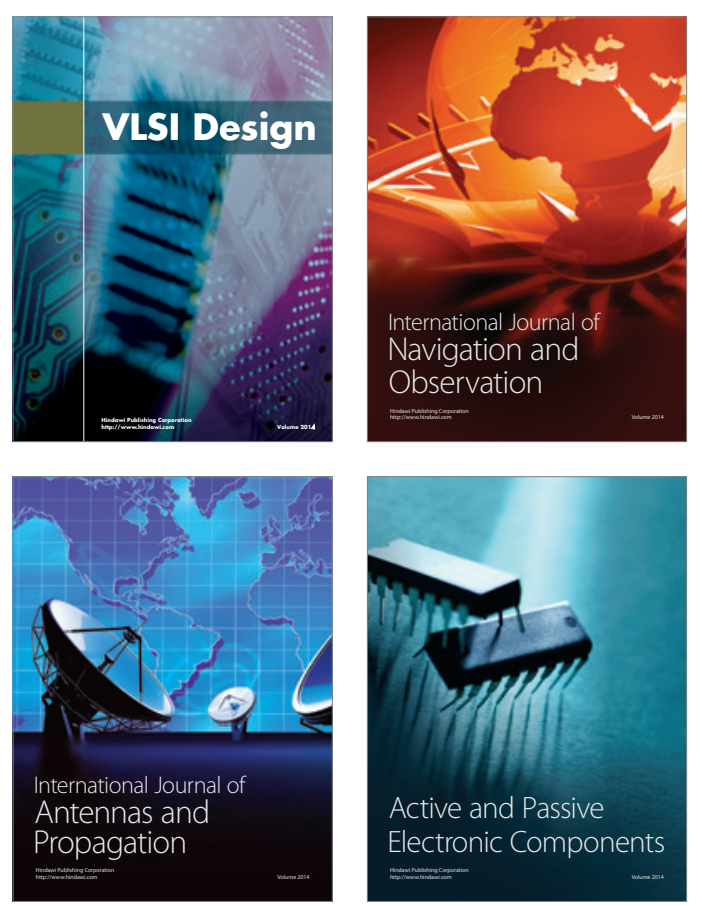
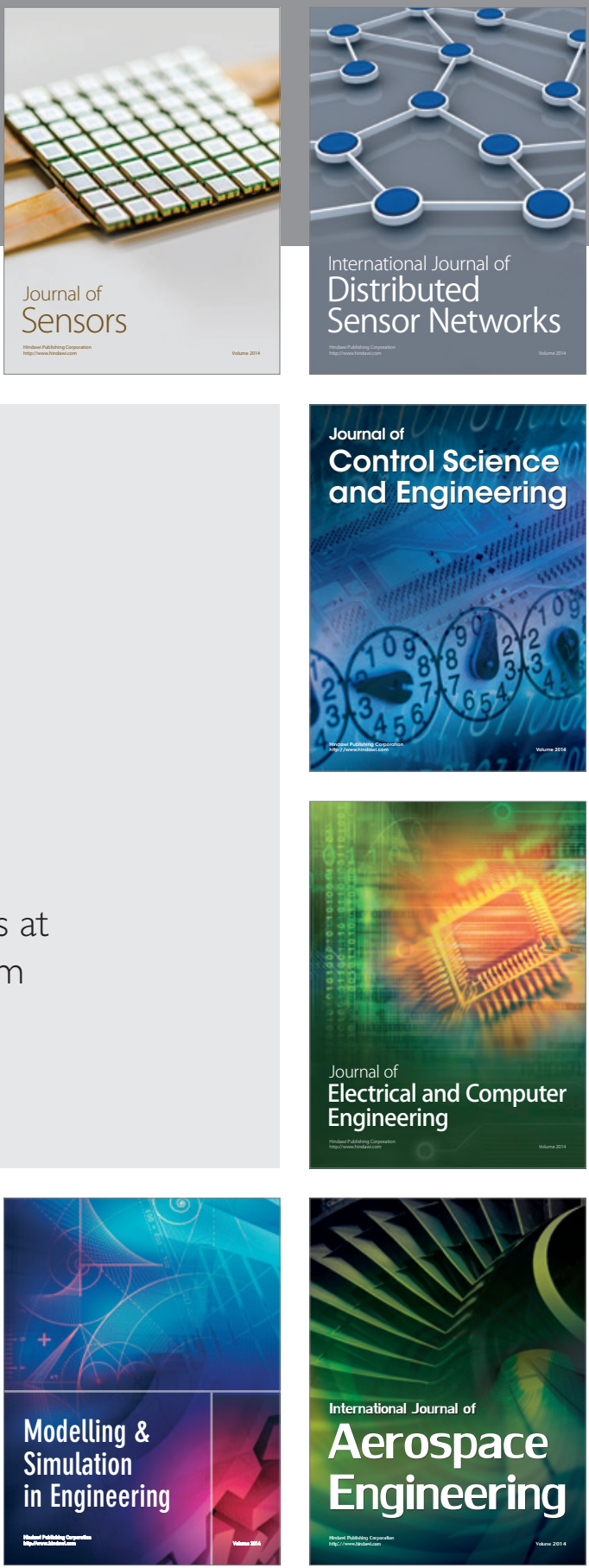

Journal of

Control Science

and Engineering
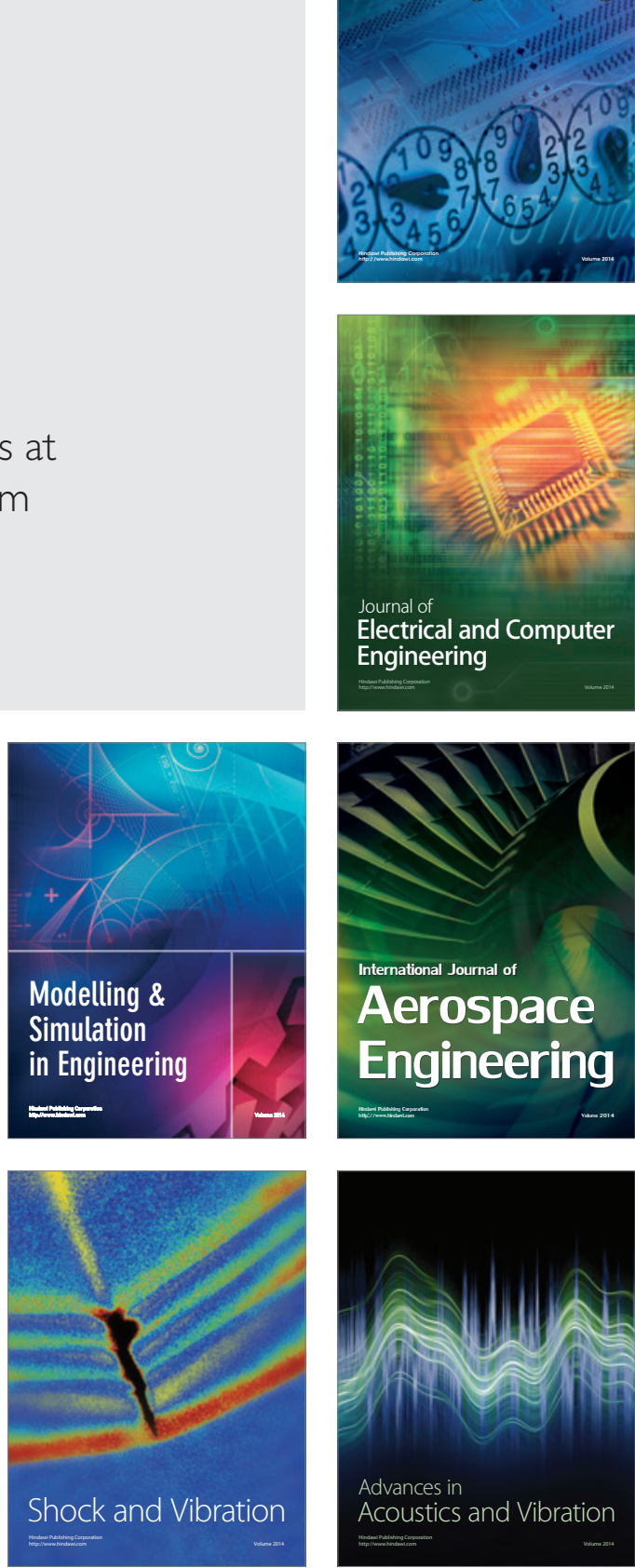